\title{
Seroprevalence and preliminary treatment of toxoplasmosis of pregnant goats in Kalubyia Governorate, Egypt
}

\author{
Mohamed Youssif Ramadan ${ }^{1}$, Afaf Desoky Abdel- Mageed ${ }^{2} \&$ Hanem Fathy Khater ${ }^{1}$
}

\begin{abstract}
Toxoplasmosis is a zoonotic disease that commonly infects goat in Egypt. For its diagnosis, sera form 48 pregnant does were tested for Toxoplasma gondii antibodies through indirect haemagglutination test (IHAT) and modified agglutination test (MAT). Samples were collected between the periods extended from November 2006 to March 2007. The seropositive rate of pregnant does (Meet Kenana, Kalubyia Governorate, Egypt) was 35.42\% (17/48). After using MAT test against $T$. gondii- IgM, 11 sera (22.9\%) were found positive. The older animals were more frequently infected (50\%) than the younger goats $(26.3 \%)$. Higher prevalence in aged does was confirmed by MAT. Total T.gondii antibodies and IgM were gradually increased with the development of pregnancy. Two months post treatment with sulfademidine $33.3 \%$, for 5 successive days at a dose of $200 \mathrm{mg} / \mathrm{kg}$, resulted in not only reduction of T.gondii total antibodies and IgM in all treated does, but re-modulation of T.gondii antibody titres moderately toward the mild titres, and prevention of congenital infection and abortion as well. Whereas IgM was not recorded in treated does, it was detected in the untreated ones. No abortion was recorded in all treated does, but an untreated doe delivered two dead fetuses. The delivered kids belonged to treated does were seropositive for $T$. gondii antibodies by using IHAT, yet they were seronegative for T.gondii- IgM by using MAT. In contrast, kids belonged to untreated does were seropositive by using both IHAT and MAT. Adequate management might be useful and essential to control toxoplasmosis in the goat herds of Kalubyia Governorate.
\end{abstract}

Key words: Toxoplasma gondii, goat, pregnancy, treatment, Egypt. 


\section{INTRODUCTION}

Goats are important popular food animals in Egypt. They are farmed for their minimal cost of rearing in addition to rapid and good production of flavored meat. Toxoplasmosis is a wide spread zoonosis caused by the coccidian protozoan Toxoplasma gondii [5,12], and it is a common infection of goat world wide $[3,7,12,17,22,30,34,38]$. It is recognized as one of the major causes of infectious reproductive failure [3,30,31].

Concerning public health importance, $T$. gondii infects about $30-60 \%$ of people worldwide. Not only meat but also milk from infected goat is a potential source for infection [31,40]. Moreover, goat's milk is now being introduced as an alternative dairy food for infants allergic to cow's milk [31]. Toxoplasmosis causes mental retardation and loss of vision in children [24]. Latent toxoplasmosis is known to induce behavioral changes because local inflammation in the brain increases dopamine, which could lead to schizophrenia [39].

Diagnosis of T.gondii depends mainly on serological tests. Indirect haemagglutination test (IHAT) is fast, accurate, and not expensive $[2,20,30]$. Intraperitoneal inoculation of a bioassay of lymph node, liver, or spleen into mice is useful and accurate as is culture of parasite in fibroblast cells [36].

Although very few epidemiological studies concerning caprine toxoplasmosis in Egypt were available $[15,17,21]$, none of them dealt with toxoplasmosis in pregnant does and its treatment.

The main objective of the present study was to determine, for the first time, the burden of T.gondii infection in pregnant does in Kalubyia Governorate, Egypt, along with its treatment at mid pregnancy by sulfadimidine $33.3 \%$.

\section{MATERIALS AND METHODS}

\section{Serum samples}

Forty-eight blood samples were collected from 48 pregnant balady goats, belonged to private farms in Meet Kenana, Tokh, Kalubyia Governorate, Egypt. The animals were at various stages of pregnancy. Does were examined for toxoplasmosis during the period extended from November 2006 to March 2007. Concerning examination of newly born kids, blood samples were taken from their jugular veins.

\section{Serological detection of T.gondii}

The frozen serum samples were thawed and used for serologic indirect haemagglutination test
(IHAT). The IHAT was performed by using commercial kits ${ }^{1}$, following the manufacture instruction.

Sera were diluted double folds from 1: 32 to 1: 512 . The titre 1:32 was considered as a negative result, while the titre 1: 64 was considered as a positive titre. Titres from 1:128 to 1: 512 were suggested to be the strongest response to infection $[14,17,34]$.

Detection of $T$. gondii $\operatorname{IgM}$ was carried out by modified agglutination test (MAT) through addition of 2 mercapto-ethanolamine [1,42].

\section{Chemotherapy}

Six pregnant does, at mid pregnancy, expressing the strongest T.gondii antibody titres, were divided into two groups (each group consisted of 3 animals). The first group ( $\mathrm{Gr} \mathrm{I}$ ) was injected, slowly intravenous, with sulfadimidine $33.3 \%{ }^{2}$ for 5 successive days $(200 \mathrm{mg} / \mathrm{kg}$ b.wt). After that, animals in the second group (Gr II) were injected with normal saline and considered as a control group. Throughout the studying period, all animals were kept indoors, received balanced ration and clean source of water, and protected from cats. Blood samples were taken from animals two months posttreatment, and serum samples were separated and stored at $-20{ }^{\circ} \mathrm{C}$ until they were used for serological studies [32].

\section{Animal inoculations}

Regarding laboratory animal inoculations, samples from brain, spleen, liver, and lymph nodes from stillborn kids were homogenized in $0.9 \% \mathrm{NaCl}$ aqueous solution. The resulting suspension was allowed to settle for $2 \mathrm{hrs}$ at laboratory temperature. Then, the supernatant was inoculated intraperitoneally into 10 adult mice. Afterwards, the peritoneal exudates were aspirated by sterile syringes after 10, 15 , and 20 days postinoculation, and slide smears were stained by Giemsa stain to detect T.gondii tackyzoites [19].

\section{RESULTS}

The prevalence of T.gondii in pregnant does (Table 1) indicated that 17 samples $(35.42 \%)$ out of 48 were seropositive for $T$. gondii by using IHAT, while IgM were detected only in 11(22.9\%) samples by using MAT. Serodiagnosis showed that goats were infected with $T$. gondii with acquisition of age. Older goats $(50 \%)$ were more likely to be seropositive than younger goats $(26.3 \%)$. Such result was confirmed by MAT, as $37.3 \%$ of elder does were seropositive versus $15.9 \%$ of younger does. Also, abortion occurred only in an aged doe. 
Seroprevalence of T.gondii during different stages of pregnancy in goats (Table 2), revealed that the total T.gondii antibodies and IgM were gradually increased with the development of pregnancy. In early pregnancy (from conception to $50^{\text {th }}$ days post conception), the higher IHAT titres 1:128 and 1:256 were recorded in 2 samples (15.4\%), and IgM was recorded in an infected doe $(7.7 \%)$. During mid pregnancy (from $51^{\text {th }}$ to $120^{\text {th }}$ day post conception), higher IHAT titres (1:128 and 1:256) were recorded in 6 samples (24\%), and IgM was recorded in 5 samples (20\%). Comparatively higher prevalences of IHAT and IgM titres, $(1: 128,1: 256$, and 1:512) were recorded in 5 samples $(50 \%)$ in late pregnancy (from $121^{\text {st }}$ day till delivery).

Treatment with sulfademidine $33.3 \%$, contributed to reduction of T.gondii antibodies in all treated does (Table 3). No abortion was recorded in the treated group, whereas an untreated doe delivered two stillborns. All delivered kids belonged to treated does were seropositive for $T$. gondii antibodies by using IHAT only. In contrast, the delivered kids related to untreated does were seropositive for $T$. gondii infection when tested by both IHAT and MAT. Diagnosis of toxoplasmosis also done by laboratory animal inoculation, and then tackyzoites were detected in Giemsa stained peritoneal exudates from all experimentally inoculated mice (Figure 1).

\section{DISCUSSION}

Goat is one of the most important animals for meat and milk production [34] which could be turned into potential sources of human toxoplasmosis. Cysts, frequently found in the brain and skeletal muscles, may remain for the remainder of the life of goat. In contrast, cattle and deer may eventually become clear of infection [5].

Toxoplasmosis not only lacks specific clinical signs or syndromes, but also can be transmitted from a recently infected mother to their fetus [29,33]. Therefore, application of laboratory diagnostic techniques is crucial for proper clinical management of pregnant does.

Table 1. Seroprevalence of Toxoplasma gondii at different periods of pregnant goats, from November 2006 to March 2007 , in Meet Kenana, Kalubyia Governorate, Egypt.

\begin{tabular}{lcccccc}
\hline \multirow{2}{*}{ Age } & Examined & \multicolumn{2}{c}{ Positive IHAT } & \multicolumn{2}{c}{ Positive MAT } & Aborted does \\
\cline { 3 - 6 } & samples (N) & $\mathbf{N}$ & \% & N & \% & \\
\hline 12-16 months & 19 & 5 & 26.3 & 3 & 15.9 & 0 \\
17- 36 months & 21 & 8 & 30.1 & 5 & 23.8 & 0 \\
Over 36 months & 8 & 4 & 50 & 3 & 37.3 & $1(12.5 \%)$ \\
\hline Total & 48 & 17 & 35.42 & 11 & 22.9 & $1(2.08 \%)$ \\
\hline
\end{tabular}

IHAT: indirect haemagglutination test. MAT: modified agglutination test.

Table 2. Seroprevalence of Toxoplasma gondii during different stages of goat's pregnancy, during the period from November 2006 to March 2007, in Meet Kenana, Kalubyia Governorate, Egypt.

\begin{tabular}{|c|c|c|c|c|c|c|c|}
\hline \multirow{2}{*}{\multicolumn{2}{|c|}{ Titres }} & \multicolumn{2}{|c|}{ Early pregnancy $(\mathrm{N}=13)$} & \multicolumn{2}{|c|}{ Mid pregnancy $(\mathrm{N}=25)$} & \multicolumn{2}{|c|}{ Late pregnancy $(\mathrm{N}=10)$} \\
\hline & & \multirow{2}{*}{$\frac{\text { IHAT }}{9(69.2 \%)}$} & \multirow{2}{*}{$\begin{array}{c}\text { MAT } \\
0\end{array}$} & \multirow{2}{*}{$\frac{\text { IHAT }}{17(68 \%)}$} & \multirow{2}{*}{$\begin{array}{l}\text { MAT } \\
\text { Non }\end{array}$} & \multirow{2}{*}{$\frac{\text { IHAT }}{5(20 \%)}$} & \multirow{2}{*}{$\begin{array}{l}\text { MAT } \\
\text { None }\end{array}$} \\
\hline 1 & 32 & & & & & & \\
\hline 1 & 64 & $2(15.4 \%)$ & 0 & $2(8 \%)$ & Non & Non & None \\
\hline 1 & 128 & $2(15.4 \%)$ & $1(7.7 \%)$ & $3(12 \%)$ & $2(8 \%)$ & Non & None \\
\hline 1 & 256 & 0 & 0 & $3(12 \%)$ & $3(12 \%)$ & $3(30 \%)$ & $3(30 \%)$ \\
\hline 1 & 512 & 0 & 0 & None & None & $2(20 \%)$ & $2(20 \%)$ \\
\hline \multicolumn{2}{|c|}{ Total (positive) } & $4(30.77 \%)$ & $1(7.7 \%)$ & $8(32 \%)$ & $5(20 \%)$ & $5(50 \%)$ & $5(50 \%)$ \\
\hline
\end{tabular}


Table 3. Effect of chemotherapy on Toxoplasma gondii antibodies in does and their fetuses, during the period from November 2006 to March 2007, in Meet Kenana, Kalubyia Governorate, Egypt.

\begin{tabular}{|c|c|c|c|c|c|c|c|c|c|}
\hline \multirow{2}{*}{$\mathrm{Gr}$} & \multirow{2}{*}{ State } & \multicolumn{2}{|c|}{ IHAT (N= 6) } & \multicolumn{2}{|c|}{$\operatorname{MAT}(\mathrm{N}=6)$} & \multirow{2}{*}{$\begin{array}{l}\text { Dead } \\
\text { fetuses }\end{array}$} & \multicolumn{3}{|c|}{ Live fetuses $(N=7)$} \\
\hline & & B & A & B & A & & $\mathbf{N}$ & IHAT & MAT \\
\hline \multirow{3}{*}{1} & 2 years (treated) & $1: 128$ & $1: 64$ & $+v e$ & -ve & None & 1 & $1: 32$ & -ve \\
\hline & 3 years (treated) & $1: 256$ & $1: 128$ & $+v e$ & -ve & None & 1 & $1: 64$ & -ve \\
\hline & 2 years (treated) & $1: 256$ & $1: 128$ & $+v e$ & -ve & None & 2 & $1: 32$ & -ve \\
\hline \multirow{3}{*}{ II } & 2 years (untreated) & $1: 128$ & $1: 256$ & $+v e$ & $+v e$ & Non & 1 & $1: 128$ & $+v e$ \\
\hline & 3 years (untreated) & $1: 256$ & $1: 512$ & $+v e$ & $+v e$ & None & 2 & $1: 128$ & $+v e$ \\
\hline & 3 years (untreated) & $1: 256$ & $1: 512$ & $+v e$ & $+v e$ & $2(33.3 \%)$ & - & - & - \\
\hline
\end{tabular}

$\mathrm{Gr}=$ Group; $\mathrm{B}=$ before treatment; $\mathrm{A}=2$ months after treatment. IHAT: indirect haemagglutination test. MAT: modified agglutination test. +ve: positive result; -ve: negative result.

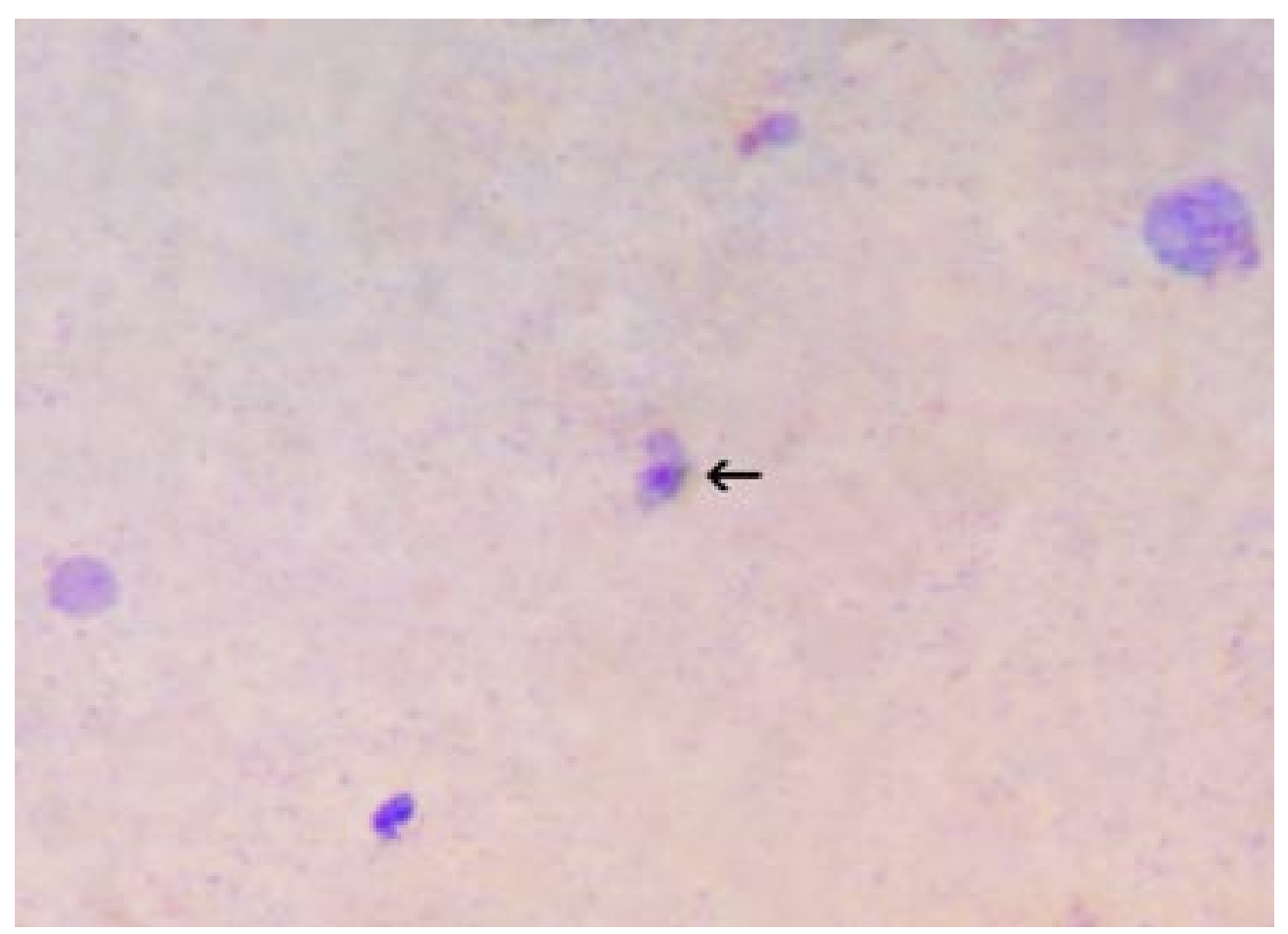

Figure 1. Tackyzoites (arrow head) in Giemsa stained peritoneal exudates from experimentally inoculated mice (X 1000).

Caprine toxoplasmosis was reported world wide $[3,7,12,22,30,38]$. Even though very few studies have been conducted in Egypt [15,17,21], nothing is known about treatment of pregnant does and the role of $T$. gondii in caprine abortion.

Our data indicated that $35.42 \%$ of the examined pregnant goats in Kalubyia Governorate were infected and developed T. gondii antibody titres without clinical signs. Pyretic period in goats after experimental infection was recorded [10]. Nevertheless, such period was not observed by the goat farmers during natural infection.

The high prevalence of $T$. gondii infection indicated continuous exposure of goats to infection due to heavy environmental contamination with oocysts shed form the observed stray cats in the farms. Similar observation was also reported in Italy [30].

The Seroprevalence result was in accordance with another Egyptian study which recorded $18.75 \%$, $28.12 \%$, and $31.25 \%$ caprine toxoplasmosis by using 
IHAT, IFAT, and ELISA, respectively, in a goat farm in Al- Amria (desert part of Alexandria Governorate, Egypt) [17].

The extent of toxoplasmosis in goat populations varied widely form flock to flock around the world. Relatively similar results were recorded, $31 \%$ in Uganda [3], 30\% in Botswana [38], 28.93\% in Brazil (Bahia State) [34], 23\% in Switzerland [7], and 27.9\% in Thailand [22].

Unlike our result, lower prevalences were recorded, $12.9 \%$ in Bangladesh [37], 12.3\% in Italy [30], $17 \%$ in Brazil (São Paulo State) [31], and $19.25 \%$ in Iran [19].

Such differences of the prevalences of caprine toxoplasmosis may be attributed to the diagnostic techniques or demographics of goat populations, breeding condition and management [30], geographic structure of $T$. gondii in relation to genetic variation [24], immune status, timing of infection, and genetic composition of the host and the organism [41], or distribution and behavior of cats [5].

In relation to age susceptibility, samples of old goats showed higher proportions of positive reactions. Such result may be attributed to prolonged exposure of elderly goats to infective oocysts throughout their life.

In the present study, we confirmed IHAT by application of MAT because IgM antibodies may fail to give information in the early diagnosis of congenital toxoplasmosis [8]. Antibodies are detectable 2 weeks post infection $[26,28]$ and maintain a low level through the host's life [27]. Accordingly, testing for IgM antibodies which appear about 1 week post infection permitted detection of recent infection of T.gondii [23]. IgM was detected by MAT in $10(12.34 \%)$ out of 48 samples. This result also agreed with a similar study, for IgM was detected in a lower percentage (5.6\%) among goats compared to $12.3 \%$ by IHAT in Italy [30]. Such values of IgM indicate true infection with $T$. gondii [6].

With regard to treatment of toxoplasmosis in pregnant does with sulfademidine $33.3 \%$, it re-modulated titres of T.gondii antibody slightly toward the mild titre, after two months post treatment. Moreover, no abortion occurred in the treated group, whereas untreated group showed higher titres, and 2 dead kids were delivered by an untreated doe. Our results concurred with a similar study which revealed that treatment of a sporadic doe by sulfonamide decreased $T$. gondii antibodies and gave birth to 2 healthy kids with normal Toxoplasma titres, 1: 16 and 1: 64 [32]. Moreover, pyrimethamine and sulfonamides given together were widely used against $T$. gondii $[25,36]$.

The detected IgM in apparently healthy kids belonged to untreated does indicated congenital toxoplasmosis, such result was in agreement with that reported by several authors [29,33].

As a consequence of toxoplasmosis, an untreated doe (33.3\%) delivered 2 stillborn kids. Abortion may occur at any time from 9 days after goats have been inoculated by $T$. gondii due to focal necrosis with mineral deposits in the cotyledons [10]. In such respect, several authors explained what could happen after infection of a pregnant doe for the first time: parasitemia occur during the first week, and the placenta becomes infected in the second followed by the fetus in the third week. Therefore, toxoplasmosis may cause fetal death with subsequent resorption, abortion, mummification, stillbirth, or delivery of weak or normal kids $[4,10,16]$. Consequently, $T$. gondii is a major cause of reproductive failure, with significant economic losses to goat breeders [3,10,12,13,16,30,31].

Toxoplasmosis is a worldwide problem which indicated that $T$. gondii oocysts contaminate the environment due to presence of large number of infected stray cats $[5,12]$. Oocysts may be shed continuously in the cat's feces from 4 until 14 days after infection, with an expected peak output of tens of millions at 6-8 days [11]. Thus, fifty grams of infected cat feces may contain as many as 10 million oocysts [11], which can remain after sporulation so for over a year [9].

Perhaps the most common source of infection is the contaminated pasture [5], and fields treated with manure and bedding from farm buildings where cats live [18]. Careless storage of farm feeds may also pose a risk [35]. Consequently, goats feed and water should be kept covered all times to prevent their contamination with cat's feces.

\section{CONCLUSIONS}

The IHAT and MAT were practical tests for rapid diagnosis of asymptomatic caprine toxoplasmosis. Older goats were more likely to be seropositive than younger goats. Caprine toxoplasmosis could be transmitted congenitally and might cause abortion or delivery of dead kids along with great economic losses. 
Treatment of infected does by sulfademidine $33.3 \%$ for 5 successive days, resulted in re-modulation of T.gondii antibodies toward mild titres, as well as prevention of congenital infection and abortion. The present data recommend that prevention of toxoplasmosis could reduce its risk through confinement, proper management, and adequate hygiene measures.
Acknowledgment. The authors would like to thank Dr. N.E. Ahmed (Faculty of Veterinary Medicine, Benha University) for her help and support.

\section{SOURCES AND MANUFACTURERS}

${ }^{1}$ FAST ABC Diagnostic, Egypt.

${ }^{2}$ Sulfadimidine sodium, Adwia Company, Egypt.

\section{REFERENCES}

1 Aly S., Elshabrawy M., Sanad M. \& Tohamy A. 2004. Serodiagnosis of acute Toxoplasma gondii infection using ELISA and Immunoblotting. The Egyptian Journal of Biochemistry and Molecular Biology. 22: 467-489.

2 Balbacha I., Hafid J., Tran M.S., Sung R., Flori P., Raberin H., Aboufatima R., Reggragui A., Dalal A. \& Chait A. 2004. Toxoplasma gondii: level of carriage in sheep of Marrakech region (Mnabha). Schweiz Arch Tierheilkd. 164: 561-564.

3 Bisson A., Maley S., Rubaire- Akiki C.M. \& Wastling J.M. 2000. The seroprevalence of antibodies to Toxoplasma gondii infection in domestic goats in Uganda. Acta Tropica. 21: 33-38.

4 Blewett D.A. 1983. The epidemiology of ovine toxoplasmosis, I. The interpretation of data for the prevalence of antibody in sheep and other host species. Brazilian Veterinary Journal. 139: 537-454.

5 Buxton D. 1990. Ovine toxoplasmosis: a review. Journal of the Royal Society of Medicine. 83: 509-511.

6 Camargo M.E., Ferreira A.W., Mineo J.R., Takiguti C.K. \& Nakahara O.S. 1978. Immunoglobulin G and immunoglobulin M enzyme linked immunosorbant assays and defined toxoplasmosis serological patterns. Infection and Immunity. 21: 55-58.

7 Chaontan-Greutmann H., Thoma R., Corboz L., Borel N. \& Pospischil A. 2002. Abortion in small ruminants in Switzerland: Investigation during two lambing seasons (1996-1998) with special regards to chlamedial abortions. Schweiz.Arch Tierheilkd. 144: 483-492.

8 Chumpitazi B.F.F., Baoussaid A., Pelloux H., Racinit C., Bost M. \& Fleuret A.G. 1995. Diagnosis of congenital toxoplasmosis by immunoblotting and relationship with other methods. Journal of Clinical Microbiology. 33: 1479-1485.

9 Dubey J.P. 1977. Toxoplasma, Hammondia, Besnoitia, Sarcocystis, and other tissue cyst- forming coccidia of man and animals. In: Kreier J.P. (Ed). Parasitic protozoa III. New York: Academic Press, pp.101-237.

10 Dubey J.P. 1988. Lesion in transplacentally induced toxoplasmosis in goats. American Journal Veterinary Research. 49: 905-909.

11 Dubey J.P. \& Frenkel J.K. 1972. Cyst-induced toxoplasmosis in cats. Journal of Protozoology. 19: 155-177.

12 Dubey J.P. \& Beattie C.P. 1988. Toxoplasmosis of animals and man. Boca Raton, Florida: CRC Press, 220p.

13 Dubey J.P. \& Adams D.S. 1990. Prevalence of Toxoplasma gondii antibodies in dairy goats from 1982-1984. Journal of the American Veterinary Medical Association. 2: 295-296.

14 Dubey J.P., Andrews C., Lind P., Howeek O. \& Tchuliez P. 1996. Antibodies response measured by various serologic tests in pigs orally inoculated with low numbered Toxoplasma gondii oocysts. American Journal of Veterinary Research. 57: 1733-1737.

15 El- Ridi A.M.S., Nada S.M.M., Aly A.S., Habeeb S.M. \& Abdul- Fattah A.A. 1990. Serological studies on toxoplasmosis in Zagazig slaughter house. Journal of the Egyptian Society of Parasitology. 20: 677-681.

16 Engeland I.V., Harald W., Hans K., Erik R. \& Oystein A. 1996. Effect of Toxoplasma gondii infection on the development of pregnancy and on endocrine foetal-placental function in the goat. Veterinary Parasitology. 67: 61-74.

17 Fahmy B.G.A. \& Ayouib M.B. 2002. Toxoplasma infection among goats with special reference to its effect on liver and kidney function. Veterinary Medical Journal of Giza. 50: 357-375.

18 Faull W.B., Clarkson M.J. \& Winter A.C. 1986. Toxoplasmosis in a flock of sheep: some investigations into its source and control. Veterinary Record. 119: 491-493.

19 Hashemi-Fesharki R. 1996. Seroprevalence of Toxoplasma gondii in cattle, sheep, and goat in Iran. Veterinary Parasitology. 61: 1-3.

20 Hove T., Lind P. \& Mukaratirwa S. 2005. Preliminary characterization of Toxoplasma gondii isolates from Zimbabwe with stage specific monoclonal antibodies. Annual of Tropical Medical Parasitology. 99: 377-382.

21 Ibrahim B.B., Salama M.M., Gawish N.I. \& Ahqridy F.M. 1997. Serological and histopathological studies on Toxoplasma gondii among the workers and the slaughtered animals in Tanta abattoir, Gharbia. Journal of the Egyptian Society of Parasitology. 27: 273-276. 
22 Jittapalapong S., Sangvaranond A., Pinyopanuwat N., Chimnoi W., Khachaeram W., Koizumi S. \& Maruyama S. 2005. Seroprevalence of Toxoplasma gondii infection in domestic goats in Satun Province, Thailand. Veterinary Parasitology. 127: $17-22$.

23 Lappin M.R., Green C.E., Prestwood A.K., Dawe D.L. \& Tarleton R.L. 1989. Diagnosis of recent Toxoplasma gondii infection in cats by the use of enzyme linked immunosorbent assay for the immunoglobulin. American Journal of Veterinary Research. 50: 1580-1585.

24 Lehmann T., Marcet P.L., Graham D.H., Dahl E.R. \& Dubey J.P. 2006. Globalization and the population structure of Toxoplasma gondii. Proceedings of the National Academy of Sciences. 103: 11423-11428.

25 Levine N.D. 1985. Veterinary Protozoology. Ames: Iowa State University Press, 413p.

26 Lin D.S. \& Bowman D.D. 1991. Cellular response of cats with primary toxoplasmosis. Journal of Parasitology. 77: $272-279$.

27 Lin D.S. \& Lisu W. 1997. Comparison of four diagnostic techniques for detecting Toxoplasma gondii infection in cats, dogs and humans. Acta Zoological Taiwanica. 8: 3-13.

28 Lin D.S., Bowman D.D. \& Jacobson R.H. 1992. Immunological changes in cats with concurrent Toxoplasma gondii and feline immunodeficiency virus infection. Journal of Clinical Microbiology. 30: 17-24.

29 Mainardi R.S., Modolo J.R., Stachissini A.V., Padovani C.R. \& Langoni H. 2003. Seroprevalence of Toxoplasma gondii in dairy goats in the Sao Paulo State, Brazil. Revista da Sociedade Brasileira de Medicina Tropical. 36: 759-761.

30 Masala G., Porcu R., Madau L., Tanda A., Ibba B., Satta G. \& Tola S. 2003. Survey of ovine and caprine toxoplasmosis by IFAT and PCR assay in Sardina, Italy. Veterinary Parasitology. 117: 15-21.

31 Meireles L.R., Galisteo Jr. A.J. \& Andrade Jr. H.F. 2003. Serological survey of antibodies to Toxoplasma gondii in food animals from Sâo Paulo State, Brazil. Brazilian Journal of Veterinary Research and Animal Science. 40: $267-271$.

32 Moya F. \& Serrato G. 1986. Treatment of toxoplasmosis in seropositive goat. Ciencias Veterinarias (Heredia). 8: 7-8.

33 Pelloux H.E., Brun G.B ., Vernet S., Marcillant S., Jolivet D., Guergour H., Hidalgo A., Fluret A. \& Ambroise-Thomas P. 1998. Determination of antitoxoplasma gondii immunoglobulinG avidity: Adaptation to the viadas system (Biomerieux). Diagnostic Microbiology and Infectious Disease. 32: 69-73.

34 Pita Gondim L.F., Barbosa H.V., Ribeiro Filho C.H. \& Saeki H. 1999. Serological survey of antibodies to Toxoplasma gondii in goats, sheep, cattle, and water buffaloes in Bahia state, Brazil. Veterinary Parasitology. 82: 273-276.

35 Plant J.W., Richardson N. \& Moyle G.G. 1974. Toxoplasma infection and abortion in sheep associated with feeding of grain contaminated with cat faeces. Australian Veterinary Journal. 50: 19-21.

36 Roberts L. \& Janovy Jr. J. 2005. Foundation of Parasitology. 7th edn. New York: Mac Graw-Hill, 137p.

37 Samad M.A., Rahman K.B. \& Halder A.K. 1993. Seroprevalence of Toxoplasma gondii in domestic ruminants in Bangladesh. Veterinary Parasitology. 47: 157-159.

38 Sharma S.P., Baipoledi E.K., Nyange J.F. \& Tlagae L. 2003. Isolation of Toxoplasma gondii from goats with history of reproductive disorders and the prevalence of Toxoplasma and chlamydial antibodies. Onderstepoort Journal of Veterinary Research. 70: 85-88.

39 Skallova A., Novotna M., Kolbekova P., Gasova Z., Vesely V., Sechovska M. \& Flegr J. 2005. Decreased level of novelty seeking in blood donors infected with Toxoplasma. Neuroendocrinology Letters. 26: 480-486.

40 Skinner L.J., Timperley A.C., Wightman D., Chatterton J.M. \& Ho-Yen D.O. 1990. Simultaneous diagnosis of toxoplasmosis in goats and goat owner's family. Scandinavian Journal of Infectious Diseases. 22: 359-361.

41 Suzuki Y. 2002. Host resistance in the brain against Toxoplasma gondii. Journal of Infectious Diseases. 185: 58-65.

42 Vitor R.W., Ferreira A.M. \& Fux B. 1999. Antibody response in goats experimentally infected with Toxoplasma gondii. Veterinary Parasitology. 81: 259-263.

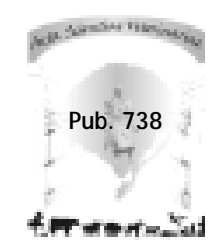

